\title{
A framework for slow physiological motion compensation during HIFU interventions in the liver: proof of concept
}

Cornel Zachiu*, Baudouin Denis de Senneville, Sjoerd Crijns, Bas Raaymakers, Chrit Moonen, Mario Ries

From Current and Future Applications of Focused Ultrasound 2014. 4th International Symposium Washington, D.C, USA. 12-16 October 2014

\section{Background/introduction}

While respiratory motion compensation for HIFU interventions for liver cancer therapy has been extensively studied, the influence of slow physiological motion, such as peristalsis, has so far been largely neglected. During the lengthy intervention, the magnitude of the latter can exceed acceptable therapeutic margins and lead to a substantial mismatch between planned ablation volume, thermal dose estimates and the measured non-perfused volume (NPV). Given the episodic nature of a HIFU intervention, this study proposes the integration of a 3D motion compensation procedure based on MR-images for slow physiological motion and validates the approach on in vivo ablations on a porcine liver.

\section{Methods \\ Overall strategy}

A volumetric HIFU ablation was completed over a time span of $2 \mathrm{~h}$ using a Phillips Sonalleve system with a respiratory gating strategy for both energy delivery and all MR-imaging. A 3D image was acquired before the first sonication, as well as after each sonication $(\Delta \mathrm{t}=5 \mathrm{~min})$ to track slow physiological motion. The estimated motion fields were used to: 1) Estimate on the planning image the position of the true ablated anatomy; 2) Register the temperature maps into the initial reference position in order to compute a correct thermal dose estimate, and 3) Register the NPV to the initial position.

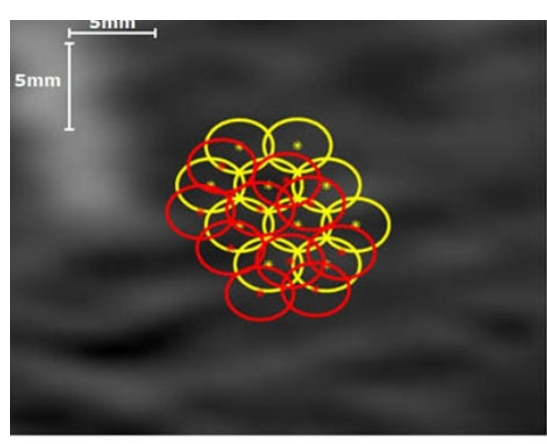

(a)

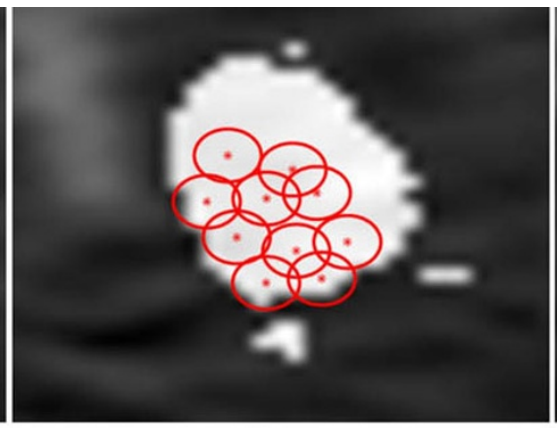

(b)

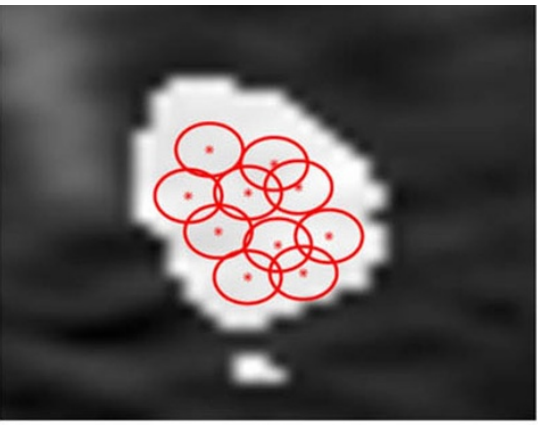

(c)

Figure 1 Planned (yellow) and motion corrected (red) sonication cluster overlaid on the corresponding anatomy in the planning image. The hyper-intense regions represent the (b) non-corrected (c) corrected location of the anatomy that receives a lethal thermal dose

University Medical Center Utrecht, Utrecht, Netherlands 


\section{Assessment of 3D liver displacements}

Liver displacements were estimated using an optical flow algorithm applied on 3D MR images.

\section{MR imaging protocol}

3D T1-weighted images were acquired on a 1.5T Philips Achieva MR scanner (Philips Healthcare, Best, The Netherlands) using the following protocol: $\mathrm{TE}=2 \mathrm{~ms}$, $\mathrm{TR}=4.3 \mathrm{~ms}$, matrix size $=192 \times 192 \times 75, \mathrm{FA}=10^{\circ}$, voxel size $=2 \times 2 \times 2 \mathrm{~mm} 3$.

\section{Results and conclusions}

Motion tracking revealed an initial shift of up to $4 \mathrm{~mm}$ during the first $10 \mathrm{~min}$, which is most likely caused by the muscle relaxant effect of anesthesia and a subsequent continuous shift due to bowel gas development of $\sim 2 \mathrm{~mm}$ until the end of the intervention. This leads to a continuously increasing mismatch of the initial shot planning, the thermal dose measurements and the true underlying anatomy as shown in Fig. 1a, 1b. The estimated displacements allowed correcting the planned sonication cell cluster positions to the true target position (Fig. 1a), as well as the thermal dose estimates (Fig. 1c) and the NPV-measurement (data not shown). A spatial coherence of all three is particularly important to assure a confluent ablation volume and to prevent remaining islets of viable malignant tissue. The in vivo experiment also demonstrates that the proposed framework is compatible with the work-flow of a HIFU intervention under clinical conditions.

\section{Acknowledgements (Funding)}

This work was supported by the STW OnTrack grant.

Published: 30 June 2015

doi:10.1186/2050-5736-3-S1-P54

Cite this article as: Zachiu et al:: A framework for slow physiological motion compensation during HIFU interventions in the liver: proof of concept. Journal of Therapeutic Ultrasound 2015 3(Suppl 1):P54.
Submit your next manuscript to BioMed Central and take full advantage of:

- Convenient online submission

- Thorough peer review

- No space constraints or color figure charges

- Immediate publication on acceptance

- Inclusion in PubMed, CAS, Scopus and Google Scholar

- Research which is freely available for redistribution

Submit your manuscript at www biomedcentral.com/submit 